\title{
THE EFFECT OF BONE BANK PRESERVATION ON THE CALCIFYING MECHANISM*
}

\author{
Leroy S. Lavine, Martin Burger and Albert E. Sobel, New York, U.S.A.
}

From the Department of Surgery, Division of Orthopaedic Surgery, State University of New York College of Medicine at New York City, and the Department of Biochemistry, Jewish Hospital of Brooklyn, New York

A fundamental orthopaedic problem to-day is the understanding of the fate of bone transplants. Since homogenous preserved bone is increasingly used, this study investigated the survival of the calcifying mechanism under storage conditions typically employed in preserving homogenous bone for orthopaedic use.

It was our hope that the method might be used to indicate the relative value of the various means of preserving bone.

The enhancement of the value of the preserved bone used in transplantation by reactivating the calcifying mechanism presented another subject of inquiry.

Calcification in vitro of the hypertrophic epiphysial cartilage of rachitic rat tibiae was employed in this study. This method is a useful indication of "local factors" involved in calcification.

The appearance of new calcification depends on the functioning of the complete system essential for mineralisation. This method is a valid one for the purpose of this investigation, for the histological appearance of calcification in vitro of the hypertrophic epiphysial cartilage resembles that obtained in calcification in vivo. New mineral deposits occur in the matrix and have a honeycomb-like structure. X-ray diffraction studies have shown that the new mineralisation obtained has the same lattice for calcification in vitro as that found for calcification in vivo, namely apatite (Sobel and Hanok 1952).

\section{PROCEDURE}

Young rats of an original Wistar strain were kept on the stock diet (Bills, Honeywell, Wirick and Nussmeier 1931) for three to four weeks. The animals were then placed on a rachitogenic diet that consisted of 75 per cent degerminated corn meal, 19 per cent wheat gluten, 2 per cent brewer's yeast, 3 per cent calcium carbonate and 1 per cent sodium chloride. De-ionised water was accessible to the rats at all times. After twenty-three to twenty-five days on this diet the rats were killed by chloroform asphyxiation. The proximal ends of the excised tibiae were freed from adhering soft tissue and sliced longitudinally, in a frontal plane, into sections approximately one millimetre in thickness.

The sliced sections were preserved by four methods used in storing bone for orthopaedic use. 1) The deep-freeze method (Bush 1947) was modified as follows. The tibial sections were stored at -20 degrees Centigrade for two weeks. Thereafter the sections were brought to room temperature and incubated at 37 degrees Centigrade for eighteen hours in an inorganic salt solution. hereafter called the calcifying solution. 2) The aqueous merthiolate method (Reynolds and Oliver 1949) was modified by soaking the tibial sections for two weeks, at room temperature, in a $1: 1000$ merthiolate solution. At the end of this time the sections were washed with 1:5000 merthiolate solution and then incubated in the calcifying solution. 3) The acetone method (Sabanas, Janes, Dahlin and Heilman 1955) consisted of soaking the tibial sections in freshly distilled acetone for two days. The supernatant was poured off and the sections were soaked again for another twelve days in freshly distilled acetone. After this interval the sections were taken from the acetone and air dried. They were then incubated in the calcifying solution. 4) In the boiling method (Lloyd-Roberts 1952) the sections were boiled for thirty minutes in distilled water. The water was poured off through a cotton gauze pledget and the sections were transferred with forceps to a small Erlenmeyer flask. The tightly stoppered flask and its contents were stored in a refrigerator at 4 degrees Centigrade.

* Reproduction in whole or in part is permitted for any purpose of the United States Government. 
After two weeks the sections were brought to room temperature and boiled again for twenty minutes in distilled water. They were then removed from the water, allowed to cool to room temperature and incubated in the calcifying solution.

Calcium chloride treatment of preserved sections-Two solutions of calcium chloride were employed. One solution contained 150 m.eq./L of $\mathrm{Ca}^{++}$and the other $500 \mathrm{~m}$.eq./ $/ \mathrm{L}$ of $\mathrm{Ca}^{+}$. After the period of storage had elapsed, the sections were shaken for one hour either in the $150 \mathrm{~m} . e q . / \mathrm{L}$ of $\mathrm{Ca} \cdot$ solution or in the $500 \mathrm{~m}$.eq./L of $\mathrm{Ca}$ solution. After this treatment the sections were rinsed with double-distilled water, blotted on a smooth filter paper, and incubated in the calcifying solution.

The stock calcium chloride solution contained 1000 m.eq./L of $\mathrm{Ca}+$ and was specially prepared from a pure grade of calcium carbonate. The conversion of the carbonate to the chloride was accomplished by adding small portions of $6 \mathrm{~N} \mathrm{HCl}$. (The concentrated $\mathrm{HCl}$ that was used was freshly distilled.) The calcium chloride solution thus obtained was evaporated to dryness, heated at 150 degrees Centigrade overnight in an oven, and diluted the next day with double-distilled water to produce a solution containing 1000 m.eq./L of $\mathrm{Ca}^{-+}$.

It is important that the presence of inhibiting ions in the calcium chloride solution be detected. This is done by shaking freshly excised rachitic tibial sections in the aforementioned calcium chloride solutions for an hour. The sections are then rinsed with distilled water and incubated in the calcifying solution. The in vitro calcification of the calcium chloride treated sections should show more intense mineralisation than the untreated control sections.

The calcifying solution was prepared by adding to a one-litre volumetric flask 100 millilitres of a stock basal salt solution* and 50 millilitres of a $\mathrm{Na}_{2} \mathrm{HPO}_{4}-\mathrm{NaH}_{2} \mathrm{PO}_{4}$ solution whose phosphorus concentration was 1 milligram per millilitre. The $\mathrm{pH}$ was lowered to 6.3 by aerating with 100 per cent $\mathrm{CO}_{2}$. To this solution were added 5 millilitres of specially prepared calcium chloride solution (see above) whose concentration was 20 milligrams per millilitre. Double-distilled water was added to the litre mark. The $\mathrm{pH}$ of the final solution was adjusted to $\mathrm{pH} 7 \cdot 3$ by aerating with 100 per cent nitrogen. A Beckmann pH meter was used.

Calcification in vitro-For in vitro calcification each section was placed in a 50-millilitre Erlenmeyer flask filled with the calcifying solution at $\mathrm{pH} 7 \cdot 3 \pm \cdot 05$. The flask was tightly stoppered with a paraffined cork and a rubber band that ran doubly over the cork and under the bottom of the flask. This precaution was taken to prevent any $\mathrm{pH}$ change. The flask and its contents were incubated at 37 degrees Centigrade for eighteen hours. After incubation the section was removed with forceps, rinsed with double-distilled water, and placed in the concavity of a glass spot plate. The section was then covered with a 3 per cent silver nitrate solution, exposed to the light from a 100 watt tungsten filament lamp for five minutes, and examined with a Leitz wide-field stereo-binocular microscope. A magnification of $32 \times$ was employed. The degree of in vitro calcification was assessed as described by Sobel $e t a l$. $(1949,1952)$ and as noted in the footnotes under Tables I and II.

Before any treatment a tibial section from each animal used in an experiment was placed in a glass plate concavity, covered with 3 per cent silver nitrate solution, and exposed to the tungsten filament light for five minutes. If a silver stain was observed in the epiphysial cartilage it indicated healing of rickets and the animal was discarded.

\section{RESULTS}

Table I summarises the methods of preservation and the degree of in vitro calcification. From these results it appears that the calcifying mechanism in the rachitic epiphysial cartilage is inactivated by the methods of preservation employed in this study.

However, when such sections were shaken in calcium chloride solutions after preservation, the results showed that $\mathrm{Ca}$ ions reactivated the calcifying mechanism. The best reactivation was obtained in the bones stored in the deep-freeze chest, for only $150 \mathrm{~m} . e q . / \mathrm{L}$ of $\mathrm{Ca}^{++}$ were required to produce a $1.5(++++)$ in vitro calcification. The bones preserved in aqueous merthiolate and in acetone showed only traces of calcification when treated with 150 m.eq./L of $\mathrm{Ca}^{++}$. However, after shaking in 500 m.eq./L of $\mathrm{Ca}^{++}$, the calcification in vitro was $2.0(++++)$ for the bones preserved by deep freezing, $1.5(++++)$ for the bones stored in merthiolate, and $1.5(++)$ for the bones stored in acetone. The boiled bones, even when shaken in $500 \mathrm{~m}$.eq./ $/ \mathrm{L}$ of $\mathrm{Ca}^{++}$, showed practically no in vitro calcification. These results represent the mean readings of at least five sections.

\footnotetext{
* The stock basal salt solution contained $0.7 \mathrm{M} \mathrm{NaCl}, 0.05 \mathrm{M} \mathrm{KCl}$ and $0.22 \mathrm{M} \mathrm{NaHCo}$ s per litre of solution. It was stored in a Pyrex brand bottle.
}

VOL. $39 \mathrm{~B}$, NO. 4 , NOVEMBER 1957 
Previous studies by Sobel et al. (1952) and by Goldenberg and Sobel (1952) on the reversibility and the survival of the calcifying mechanism suggested that it might be possible to prevent inactivation of the calcifying mechanism during deep-freeze storage. Accordingly, fresh rachitic tibial sections were shaken for one hour in 150 m.eq./L of $\mathrm{Ca}^{++}$. Excess calcium

TABLE I

Calcification In Vitro After Various Methods of Bone Preservation Before and After Treatment with Calcium Ions

\begin{tabular}{|c|c|c|c|c|}
\hline \multirow{2}{*}{\multicolumn{2}{|c|}{$\begin{array}{l}\text { Method of } \\
\text { preservation }\end{array}$}} & \multicolumn{3}{|c|}{ Degree of in vitro calcification* } \\
\hline & & $\begin{array}{l}\text { No } \\
\text { treatment }\end{array}$ & $\begin{array}{l}\text { Treatment with } \\
150 \text { m.eq./L Ca }{ }^{++}\end{array}$ & $\begin{array}{l}\text { Treatment with } \\
500 \text { m.eq./L Ca }{ }^{++}\end{array}$ \\
\hline Deep free & & $0(0)$ to trace & $1 \cdot 5(++++)$ & $2 \cdot 0(++++)$ \\
\hline Aqueous & thiolate & $0(0)$ & trace & $1 \cdot 5(++++)$ \\
\hline Acetone & . & $0(0)$ & trace & $1 \cdot 5(++)$ \\
\hline Boiling & . & $0(0)$ & $0(0)$ & trace \\
\hline Control . & . & $2 \cdot 0(++++)$ & $2 \cdot 0(++++)$ & $3 \cdot 0(++++)$ \\
\hline
\end{tabular}

* The degree of calcification is indicated as follows: $0(0)$ no calcification; $1(+)$ trace; $1(++)$ broken thin line; $1(+++)$ almost complete thin line across the provisional zone; $1(++++)$ complete thin line across the provisional zone; $2(++++)$ heavy line across the provisional zone including the primary tongues of cartilage; $3(++++)$ heavy line across the provisional zone including the primary and secondary tongues of cartilage; $4(++++)$ practically complete calcification of the metaphysis.

TABLE II

Influence of Calcium Ions on Metachromasia of Deep-frozen Rachitic Tibial Sections

\begin{tabular}{|c|c|c|c|c|c|}
\hline \multirow{2}{*}{$\begin{array}{l}\text { Toluidine blue } \\
\text { in solution, } \\
\mathrm{uM} / \mathrm{L}\end{array}$} & \multirow{2}{*}{$\begin{array}{l}\mathrm{CaCl}_{2} \text { in } \\
\text { solution } \\
\text { (m.eq./L) }\end{array}$} & \multicolumn{4}{|c|}{ Degree of metachromasia* in sections treated by: } \\
\hline & & $\begin{array}{c}\text { Deep freezing } \\
\text { only }\end{array}$ & $\begin{array}{l}\mathrm{CaCl}_{2} \text { before } \\
\text { deep freezing }\end{array}$ & $\begin{array}{l}\mathrm{CaCl}_{2} \text { after } \\
\text { deep freezing }\end{array}$ & $\begin{array}{l}\text { Untreated } \\
\text { controls }\end{array}$ \\
\hline 39 & 0.0 & 0 & + & ++ & \pm \\
\hline 39 & $5 \cdot 0$ & \pm & + & ++ & ++ \\
\hline 39 & $10 \cdot 0$ & ++ & ++ \pm & +++ & ++++ \\
\hline 39 & $25 \cdot 0$ & + & ++ & ++ & ++ \\
\hline 39 & $50 \cdot 0$ & \pm & + & ++ & + \\
\hline 39 & $100 \cdot 0$ & 0 & 0 & $\mathbf{0}$ & \pm \\
\hline 39 & $200 \cdot 0$ & $\mathbf{0}$ & 0 & 0 & 0 \\
\hline
\end{tabular}

* The degree of metachromasia was graded as follows: $0=$ No purple (metachromatic) stain. $\pm=$ Broken thin line of metachromatic staining extending across the epiphysial hypertrophic cartilage. $+=$ Continuous thin line of metachromatic staining extending across the epiphysial hypertrophic cartilage. $++=$ Continuous line of metachromatic staining extending across the epiphysial hypertrophic cartilage and half way up. $+++=$ Continuous line of metachromatic staining extending across the epiphysial hypertrophic cartilage and three-quarters of the way up. $++++=$ Complete metachromatic staining of the hypertrophic cartilage.

solution was removed by washing the sections with three changes of distilled water. The sections were then placed in the deep-freeze chest for two weeks. At the end of this time the sections were brought to room temperature and incubated in the calcifying solution. In vitro calcification readings of $1.5(++++)$ were obtained, thus proving that the calcifying 
mechanism had survived the deep-freeze treatment. Control sections that had not been shaken in the calcium chloride solution were inactivated. Fresh, untreated control sections gave $2(++++)$ in vitro calcification readings.

The influence of deep-freeze preservation on metachromatic activity of the epiphysial cartilage was also investigated. The procedural details and the method of assessing the degree of metachromasia have been described by Sobel and Burger (1954). Further details on metachromasia and the role of chondroitin sulphate in the calcifying mechanism have been discussed by Sobel (1955).

Briefly the deep-freeze preserved sections showed zero metachromasia when soaked for eighteen to twenty hours in a toluidine blue $0^{*}$ solution containing 2.5 milligrams of the dye per 100 millilitres of solution. Parallel sections soaked in the dye and containing, in addition, 10 m.eq./L of $\mathrm{Ca}^{++}$gave a +++ stain. The presence of calcium ions was indeed required in the active calcifying molecule. Metachromasia was markedly enhanced when deep-frozen sections were shaken with calcium ions and then soaked in the dye solution. Similarly, when sections were treated first with calcium ions followed by deep-freeze storage, the metachromasia was again enhanced.

Table II portrays the results obtained, based on a calcium curve procedure previously described (Sobel and Burger 1954).

\section{DISCUSSION}

The calcifying mechanism present in the hypertrophied proliferating epiphysial cartilage is inactivated by all four methods of preservation. This inactivation is almost completely reversed in the case of frozen bone after treatment with calcium chloride. Moreover, the inactivation can be prevented by prior treatment with calcium chloride. In the case of boiled bone the inactivation apparently is not reversible and probably represents destruction of the mechanism responsible for calcification in vitro. The other two methods occupy intermediary positions with respect to reversibility.

The inactivation after freezing is of particular interest because this represents conditions under which many enzymes are preserved. It is likely that calcium ions were stripped off from a critical position because calcium chloride treatment restored the mechanism. One can visualise during the freezing process a change in shape as well as length of large molecules such as collagen and mucopolysaccharides such as chondroitin sulphate. The nature of a combination of these two compounds would probably undergo a change as a result. One can easily conceive that the calcifying mechanism which was postulated to be homologous to collagen chondroitin sulphate (Sobel and Burger 1954) underwent a reversible rearrangement to an inactive form.

If the mechanism of calcification in true bone is closely related to the mechanism in the pre-osseous cartilage, these findings would imply that freezing, either followed or preceded by calcium chloride treatment, may be a more desirable method of bone bank preservation than methods now used. We hope that further studies in progress will elucidate this point.

\section{SUMMARY}

1. The influence of various methods of preserving bone on the calcifying mechanism of the tibial epiphysial cartilage of rachitic rats was studied. An in vitro calcification technique was employed.

2. Preservation by deep freezing, aqueous merthiolate, boiling, or acetone inactivated the calcifying mechanism.

3. The inactivation was reversed with calcium ions, most readily in the deep-frozen bones, less readily in the merthiolate treated bones, still less readily in the acetone stored bones, and least in boiled bones.

* Toluidine blue 0 obtained from Hartman-Leddon Co., Philadelphia. 
4. Exposure to calcium ions before preservation in the deep-freeze chest prevented inactivation. 5. The inactivation, reactivation and survival of the calcifying mechanism were confirmed by metachromasia studies.

6. The theory of the mode of action of calcium chloride on reactivation and survival of the calcifying mechanism is presented.

These studies were supported in part by a contract between the Office of Naval Research, Department of the Navy, and the Jewish Hospital of Brooklyn, NR 180 025; by funds provided under contract AF18(600)-1274 with the U.S.A.F. School of Aviation Medicine, Randolph Field, Texas; and by funds from Research Grant D.55 from the National Institute of Dental Research, National Institute of Health, Public Health Service.

\section{REFERENCES}

Bills, C. E., Honeywell, E. M., Wirick, A. M., and Nussmeier, M. (1931): A Critique of the Line Test for Vitamin D. Journal of Biological Chemistry, 90, 619.

Bush, L. F. (1947): The Use of Homogenous Bone Grafts. A Preliminary Report on the Bone Bank. Journal of Bone and Joint Surgery, 29, 620.

GoldenberG, H., and Sobel, A. E. (1952): Calcification IX. Influence of Alkaline Earths on Survival of the Calcifying Mechanism. Proceedings of the Society for Experimental Biology and Medicine, 81, 695.

Lloyd-RoberTs, G. C. (1952): Experiences with Boiled Cadaveric Bone. Journal of Bone and Joint Surgery, 34-B, 428.

Reynolds, F., and Oliver, D. R. (1949): Clinical Evaluation of the Merthiolate Bone Bank. Journal of Bone and Joint Surgery, 31-A, 792.

Sabanas, A. O., Jones, J. M., Dahlin, D. C., and Heilman, F. R. (1955): Comparison of Homologous Bone Grafts Preserved by Acetone and Formaldehyde and by Acetone Alone: Experimental Studies. Proceedings of the Staff Meetings of the Mayo Clinic, 30, 432.

Sobel, A. E. (1950): The Local Factor in Calcification. Metabolic Interrelations. Transactions of the Second Conference, p. 113. New York: Josiah Macy, Jr., Foundation.

Sobel, A. E. (1955): Local Factors in the Mechanism of Calcification. Annals of the New York Academy of Sciences, 60, 713.

Sobel, A. E., Nobel, S., and Hanok, A. (1949): The Reversible Inactivation of Calcification in vitro. Proceedings of the Society for Experimental Biology and Medicine, 72, 68.

SOBEL, A. E., and HANOK, A. (1952): Calcification VII. Reversible Inactivation of Calcification In Vitro and Related Studies. Journal of Biological Chemistry, 197, 669.

SOBEL, A. E., and Burger, M. (1954): Calcification XIV. Investigation of the Role of Chondroitin Sulfate in the Calcifying Mechanism. Proceedings of the Society for Experimental Biology and Medicine, 87, 7. 